\title{
Trois études sur un passage du Rouge et le noir
}

The three following articles treat various aspects of a passage in Stendhal's Le Rouge ct le noir as transcribed below.

1 Cette magnificence mélancolique, dégradée par la vue des briques nues et

2 du plâtre encore tout blanc, toucha Julien. Il s'arrêta en silence. A l'autre

3 extrémité de la salle, près de l'unique fenêtre par laquelle le jour pénétrait

4 il vit un miroir mobile en acajou. Un jeune homme, en robe violette et en

5 surplis de dentelle, mais la tête nue, était arrêté à trois pas de la glace. Ce

6 meuble semblait étrange en un tel lieu, et, sans doute, y avait été apporté de

7 la ville. Julien trouva que le jeune homme avait l'air irrité; de la main

8 droite il donnait gravement des bénédictions du côté du miroir.

9 Que peut signifier ceci? pensa-t-il. Est-ce une cérémonie préparatoire

10 qu'accomplit ce jeune prêtre? C'est peut-être le secrétaire de l'éveque...il

11 sera insolent comme les laquais..ma foi, n'importe, essayons.

12 Il avança et parcourut assez lentement la longueur de la salle, toujours

13 la vuc fixcée vers l'unique fenĉtre et regardant ce jene bomme que

14 continuait à donner des bénédictions exécutées lentement mais en nombre

15 infini, et sans se reposer un instant.

16 A mesure qu'il approchait, il distinguait mieux son air fâché. La richesse

17 du surplis garni de dentelle arrêta involontairement Julien à quelques pas du

18 magnifique miroir.

19 Il est de mon devoir de parler, se dit-il enfin; mais la heauté de la salle

20 l'avait ému, et il était froissé d'avance des mots durs qu' on allait lui

21 adresser.

22 Le jeune homme le vit dans la psyché, se retourna, et quittant subitement

23 l'air fâché, lui dit du ton le plus doux:

24 -Eh bien! Monsieur, est-elle enfin arrangée?

25 Julien resta stupéfait. Comme ce jeune homme se toumait vers lui,

26 Julien vit la croix pectorale sur sa poitrine: c'était l'évêque d'Agde. Si

27 jeune, pensa Julien; tout au plus six ou huit ans de plus que moi!...

28 Et il eut homte de ses éperons.

Stendhal, Le Rouge et le noir. Paris: Gallimard (Pléiade), 1952, 314-315. 